\title{
Research on Urban Light Pollution and Its Prevention
}

\author{
Xuan $\mathrm{Hu}$ \\ School of Electrical Engineering, North China Electric Power University, Baoding 071003, China \\ 1211265271@qq.com
}

Keywords:light pollution, visible light, dazzle.

\begin{abstract}
With the fast development of urbanization, a large number of landmark buildings have been built, most of which are provided with glass curtain walls which can produce light pollution when they are projected with natural lights and lights from human resources. Nowadays, light pollution has become increasingly serious, which poses a great threat to human production, living and people's physical and mental health. This paper makes a summary of urban light pollution, discusses the causes of its production, points out its influence on human physical health and finally puts forward specific measures from the angle of physical prevention control for preventing urban light prevention.
\end{abstract}

\section{The concept and status quo of light pollution}

Light pollution, in broad sense, is the general term for the negative effects of visible light, ultraviolet radiation and infrared radiation on human health and human living environment. There are three kinds of light pollution in the world, which is white light pollution, artificial daylight and color light pollution.. For example glass curtain wall of illumination and reflection and refraction, building or building landscape lighting, road and traffic lighting, square or site lighting, advertising signs lighting and garden landscape lighting the escape of astigmatism, plant growth and ecological environment produced negative effects are known as light pollution ${ }^{[1]}$.

Since the last century 70's scholars have proposed the concept of light pollution, and now the more 40 years. Excessive nighttime lighting and glass curtain wall make the phenomenon of light pollution increasingly serious in the city. Examples of light pollution everywhere in our daily life. My house in the vicinity of 200 meters is the local famous lobster street, in order to attract customers, and establish a lot of billboards night of nearby residents, produced the serious light pollution, hindered the sleep quality of residents. Light pollution during the day also occurs. Modern urban construction uses a large number of reflective of the decorative material, the strong sunlight reflected by the sun may produce glare. The glare pollution is the main form of the light pollution in the city, and is one of the most important factors that affect the quality of the lighting ${ }^{[2]}$.

Light pollution in developed countries are more common, according to the relevant statistics, the German light pollution in growth rate of $6 \%$, Italy and Japan is currently $10 \%$ and $12 \%$, about $99 \%$ by light pollution of life of people in Europe and the United States (excluding Alaska and Hawaii) ${ }^{[3]}$. According to the satellite images of the map, we can see the light pollution situation of the United States.Especially in the eastern coastal areas of the United States, light pollution is very serious. From day to night. The light pollution is always present in our life, threatening human health.. Because of the influence of light pollution to the normal life order, the research on the mechanism of light pollution is getting deeper and deeper.

\section{Urban light pollution causes and damage}

According to the wavelength of light pollution can be divided into visible light pollution, infrared pollution and ultraviolet pollution of three kinds of. The influence of the infrared and ultraviolet pollution in the daily life of the residents is far from the visible light pollution.

The main cause of the urban light pollution is the large amount of glass curtain wall and excessive lighting equipment in the city. These cause visible light pollution.. The city lacks the reasonable and effective layout, for the relevant advertising lights lack of relevant regulations. Urban buildings adopt 
a large area of mirror type aluminum alloy decorative facades or glass curtain wall in the direction and time of the characteristics of the sun light. Urban night lighting lamps, with the rapid development of night scene lighting, high power gas discharge light source widely used, even in the night as bright as day. Ordinary visible light pollution can give people's eyes bring visual fatigue, and glare is the biggest hazard in light pollution. Glare pollution is the main factor that affects the quality of lighting. Glare is an important indicator of the comfort of the environment, according to the special formula can calculate the relative glare index. More than 28 of the deemed just cannot stand.

The effects of light pollution mainly on the human sleep quality and the generation of irritability. People who are chronically affected by light pollution will have a strong sense of discomfort in the body and psychology. If people work or learn in the environment that exceed the national illumination standards, the retina will suffer from the damage of different degrees, the vision will drop sharply, the incidence rate of cataract is as high as $45 \%$. The effects of light pollution on the human body are trace and cumulative.

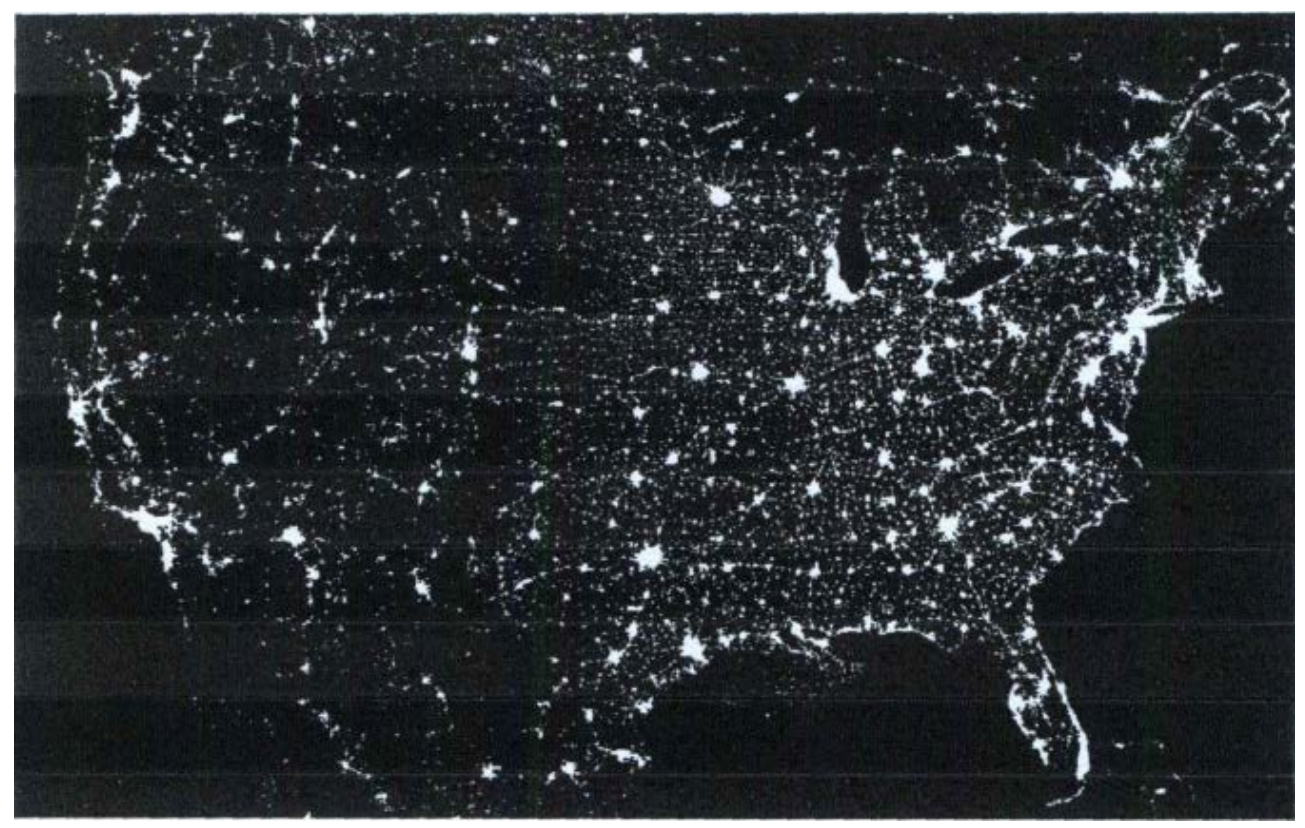

Fig 1.United States Land light pollution situation

The harmfulness of the light pollution is also reflected in the transportation system. Recently a traffic police to punish improper use high beam lamps are discussed in a hot debate. A traffic police on duty on a poor light beam for 15 minutes straight to the owner of the punishment. Some people think that this has infringed the basic rights and interests of the driver and very opposed. By what kind of punishment measures do not discuss, but improper use the high beam light may produce glare, while driving to opposite the driver brought great insecurity. Numerous improper use of the light produced by the traffic accident.

The same light pollution also brings a lot of adverse effects on the growth of the astronomical observation and the plants and plants.

\section{Light pollution prevention and control}

The direct glare degree is mainly related to the correlation index such as the luminous surface size and the luminance of the light emitting surface.. For the light of the light source, lamps, lighting, etc. Limit direct glare from the use of transparent material or light control of the protective angle of these two aspects. In addition to adjust the reflection ratio and background brightness can also control the generation of glare.

In addition to direct glare, the reflection of the glare than the direct glare of the greater impact of the glare, the reflection glare close to the line of sight, eyes cannot directly avoid the serious, will lead to transient blindness. Control the reflection glare should start from the reasonable layout, if the 
lamp's brightness no way down to the following requirements, adjust the position of the working surface, so that the reflex angle cannot be in sight. But this method is difficult to realize in some degree. At this time can increase the amount of light source to improve the illumination, and appropriate to improve the brightness of the environment is also feasible to reduce the contrast.

Infrared ray is a kind of heat radiation, will produce heat in the human body, causing heat burn of the human body. The excessive ultraviolet light can cause the human immune system to be severely suppressed, may cause the disease incidence rate to increase. The control of infrared ultraviolet pollution is mainly in the pollution source and receiver. There is a need for safe and ultraviolet pollution, and people should wear protective glasses and masks in the places where they are contaminated, and strengthen the personal protective measures.

Reasonable urban design and scientific management technology is the fundamental strategy of harnessing light pollution. At present, in Paris, France has set out to establish a designed to protect the historical style of the city night atmosphere of night lighting planning, in Venice, Italy, is also in order to protect the ancient city style and features, and the development of lighting construction planning, the city maintains a low illumination. In the case of the protection of road lighting should make a limit on the excess night scene lighting. Reduce the harmful light to the level of the environment and the people harm, and use the light as little as possible, improve the light efficiency.

Because of the serious light pollution, the developed countries began to study the relevant legislation. Similarly, in August 2008, the government of the Hong Kong government launched the preparatory work for the light pollution legislation.. The Macao area in March 11, 1991 implemented the environmental outline law clearly defined the light brightness. Taiwan environmental protection agency in February 2010 in Taiwan north, South China, the 22 LED advertising screen made a light pollution survey, found that the brightness is 115 times CIE recommended standard value.

With the rapid development of China's economic and social, light pollution problems are becoming more and more serious, urban light environment deterioration trend, light pollution problem has already increased, will become negative factors that affect the city's ecological environment and social harmony and stability. The lack of light pollution prevention legislation, the supervision is not in place, the system is not perfect, the legal responsibility is not clear and so is the main cause of light pollution in China ${ }^{[4]}$.

The legalization of environmental pollution control is the manifestation of the progress of human society civilization, but also the inevitable requirement for the rule of law to govern the country by pollution. China's light pollution prevention and control has just started, on the one hand, China light pollution incidents continue to increase, on the other hand, China's legislation on light pollution is still a blank, it is urgent to set up the corresponding legal system management of the environmental problems. Along with the deepening of the scientific recognition of light pollution, the field of light biological effect is still waiting for scientific exploration and research.. Therefore, conform to the conditions of the legislative mode, establish perfect supervision system, the development of health based light pollution prevention technical standard system, perfect the legislation on light pollution, comprehensive prevention and control of light pollution, protection of human health and ecological balance, building a comfortable, green, harmony, sustainable development of ambient light target.

\section{Reference}

[1] Wang Zhen: urban light pollution prevention and control strategy(Master Degree,Tongji University,China,2007).P.27

[2] Chen Jierong .physical pollution control.Higher Education Press, 2007,p.249-273

[3] Ni Yonghua. The German city of light pollution is increasingly serious, the Yangtze Evening News, 2002-9-16.

[4] Wang Dong, Luo Qixiu, et al: research and Discussion on the legislation of light pollution prevention and control, environmental science and management, 2011.No2,p.36-40. 